\title{
Soil organic matter dynamics: land use, management and global change
}

\author{
M. Francesca Cotrufo • Richard T. Conant • \\ Keith Paustian
}

Received: 14 October 2010 /Accepted: 15 October 2010 /Published online: 28 October 2010

(C) Springer Science+Business Media B.V. 2010

Soil organic matter (SOM) is one of the most complex components of terrestrial ecosystems and serves many vital functions in terms of regulating the flow and supply of nutrients to plants, regulating water flow and water retention in soils and determining the physical attributes of soils. Hence, the maintenance and management of SOM is vital for the sustainability of croplands, grasslands, forests and wetlands. More recently, increased attention has been focused on the role of soils in the global carbon cycle, where the world's soils contain more than 1.5 trillion tonnes of carbon or roughly three times the carbon contained in all the world's vegetation and twice the amount of carbon $\left(\right.$ as $\left.\mathrm{CO}_{2}\right)$ in the earth's atmosphere. Hence, relatively small changes in the global storage of carbon in SOM can have large effects on greenhouse gas (GHG) concentrations - either positively or negatively. If soils are managed to increase their organic

Responsible Editor: Hans Lambers.

M. F. Cotrufo $(\bowtie) \cdot$ R. T. Conant $\cdot$ K. Paustian

Colorado State University,

Fort Collins, CO, USA

e-mail: cotrufo@nrel.colostate.edu

R. T. Conant

Queensland University of Technology,

Brisbane, QLD, Australia matter content (which also contributes to increased soil fertility), $\mathrm{CO}_{2}$ levels in the atmosphere can be reduced. Currently there is a growing interest in promoting soil carbon sequestration as a GHG mitigation option, particularly in many developing countries. Incorporating carbon sequestration objectives in sustainable land management projects (both via the growing voluntary GHG offset markets and evolving national and international GHG mitigation policies) opens the possibility to radically improve the prospects for improved livelihoods and more sustainable land use practices in developing countries.

Research directed at improving our understanding of, and ability to accurately predict, changes in SOM, across the range of managed ecosystems - from croplands, grazing lands, forests and wetlands - is moving very rapidly. Increasingly the science community is being called upon to provide the information and tools needed to support policies directed towards sustainable land use and GHG mitigation, involving SOM.

With the overall aim to present the state-of-the-art on SOM studies across the world and highlight future research directions, the International Symposium on Soil Organic Matter Dynamics: Land Use, Management and Global Change was held in Colorado Springs, Colorado, USA, on July 6-9, 2009 (http:// www.nrel.colostate.edu/som-home.html). At the symposium, SOM dynamics were discussed in the context 
of a wide variety of topics, including climate change, $\mathrm{N}$ interactions, land-use and -management activities, flooded and high-latitude/high-altitude environments and microbial and enzymatic controls. Soil carbon quantification for GHG accounting was also featured, and a session was dedicated to discuss the consequences of biofuel-production systems for soil carbon and GHG balance. A strong emphasis was given to the discussion of new methods for characterization of SOM structure and properties. The Symposium placed current SOM research in a historical perspective with invited keynote lectures on the past history of SOM studies, as well as a forward look at SOM research in future decades.

This Special Issue presents a set of peer-reviewed papers that were first presented at the symposium, and that span the range of the topics discussed. Broadly, the papers are grouped in the Special Issue as 1) field studies focusing on land-use and -management impacts on SOM, 2) field and laboratory studies of SOM characterization and soil biotic and biochemical controls on SOM, 3) modeling and measurement approaches to understand and quantify SOM changes and 4) climate change and soil carbon.

Cerri et al., Hopkins et al. and Sainju et al. report on SOM responses to tillage and agronomic management in the Amazon frontier of Brazil, in Scotland (UK), and North Dakota (USA), respectively. SOM and various aspects of grasslands and grazing management are discussed in papers by Handayani et al., Riedell et al. and Steffens et al., while Recous et al. focus on quality and decomposition of Miscanthus grass grown as an energy crop.

Work focusing more on fine-scale, microbialrelated processes include two papers by Baldrian et al. on SOM and soil enzymes, while questions regarding decomposition and stabilization processes in deeper soil horizons and how they differ from the more frequently investigated surface soils are addressed by Chabbi et al. and in a review by Rumpel et al. Gentile et al. examine the role of litter quality on SOM at different time scales and Ono et al. report on humification processes of needle litter for different coniferous forest plantations. Spohn et al. described fractionation methods used to understand long-term
SOM dynamics in sandy hydromorphic soils with low carbon stabilization capacities.

Papers with a focus on modeling and/or measurement approaches for quantifying SOM and litter dynamics, range from more mechanistic, research-oriented approaches involving SOM carbon and nitrogen interactions (Eliasson et al.) and litter quality impacts on decomposition (Borgen et al.), to a simple applied soil carbon assessment model (Franzluebbers et al.) and use of spectral reflectance measurements to quantify soil carbon (Kusumo et al.). Van Wesemael et al. review the rationale and designs of current soil carbon monitoring for existing and planned soil monitoring networks to support soil carbon inventories and mitigation policies.

Alvaro-Fuentes et al. and Sommer et al. analyze impacts of climate and land use on soil carbon and the potential for soil carbon sequestration on managed lands in Spain and Central Asia, respectively. Finally, Martí-Roura et al. report on SOM changes as affected by fire frequency and drought stress, key disturbance regimes that will likely be affected by climate change.

The Symposium was the second of a series of international meetings on SOM, with the first entitled "Organic Matter Dynamics in Agroecosystems" being held in Poitiers, France, on July 16-19, 2007 and the third entitled "SOM2011: Organic matter dynamicsfrom soils to oceans" to be held in Leuven, Belgium on July 11-14, 201 (http://ees.kuleuven.be/som2011/ index.html).

The 2009 symposium in Colorado was cosponsored by USDA's National Institute for Food and Agriculture (NIFA), Agricultural Research Service (ARS) and Natural Resources Conservation Service (NRCS), the US Department of Energy-Office of Science, Colorado State University's College of Agricultural Sciences and Warner College of Natural Resources, Carbon Management Center of the Colorado Clean Energy Collaboratory, International Plant Nutrition Institute (IPNI) and $25 \times 22$. We want to thank all the participants (Fig. 1) that made this Symposium a most interesting and inspiring event and the sponsors for making it possible. 


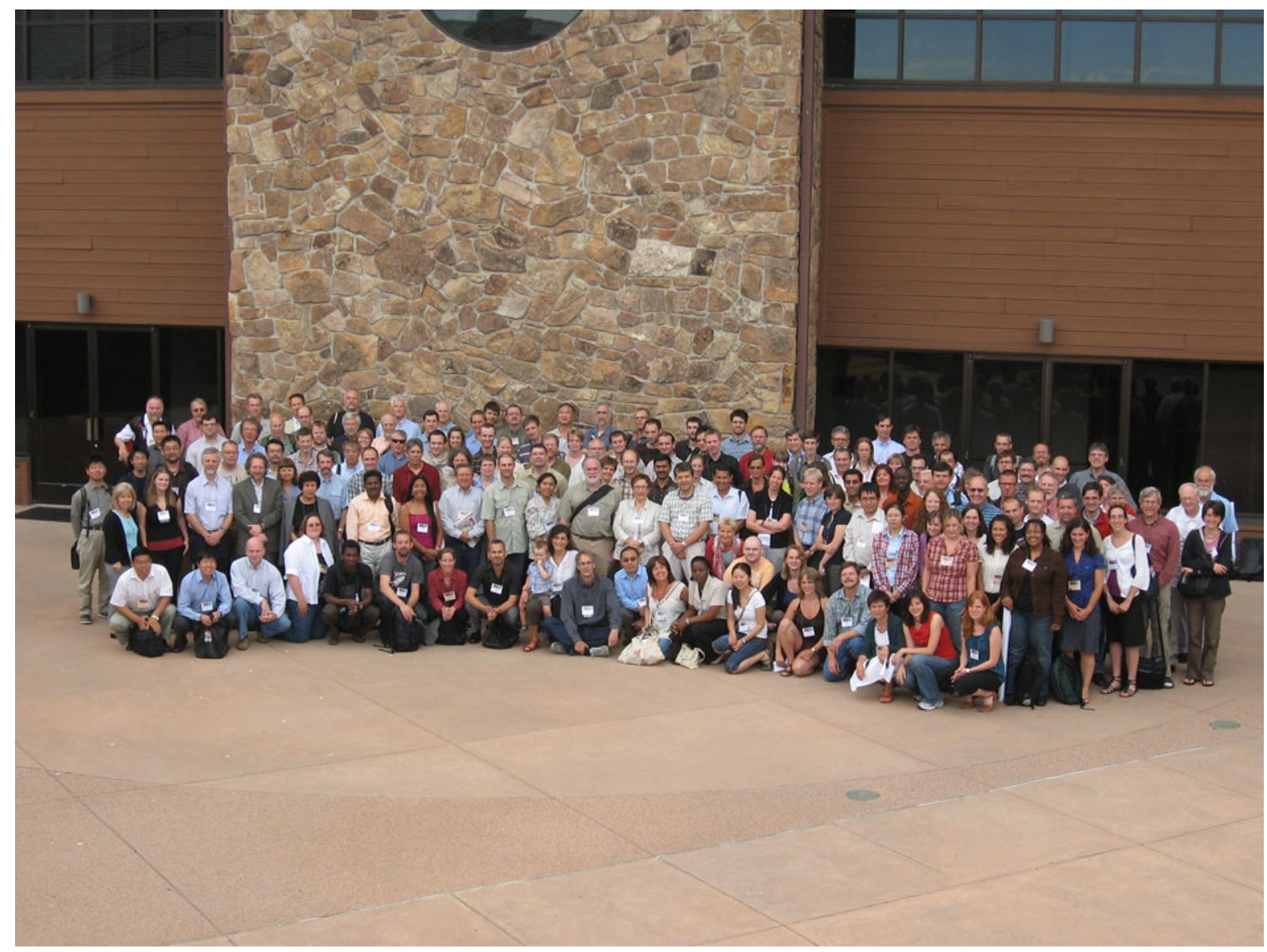

Fig. 1 Group picture of the participants to the International Symposium on Soil organic matter dynamics: land use, management and global change 